\title{
Communications Committee Update
}

\author{
Dylan Burger \\ Deputy Editor, Hypertension News \\ Chair, ISH Communications Committee \\ University of Ottawa, Canada
}

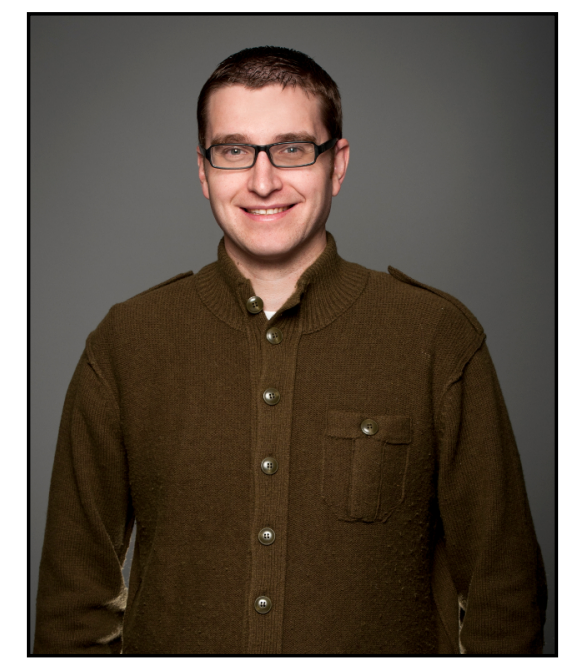

It is my sincere honour to have the opportunity to serve as chair of the ISH Communications Committee from 2018 - 2020. Communication is something that I feel is essential to the short and long-term growth of the ISH and I look forward to working with the ISH Executive, incoming Communications, and ISH Membership Committees in the coming years.

As has traditionally been the case, the Communications Committee will be divided into two distinct entities. The Hypertension News Editorial Board (led by editor Lars H. Lindholm) and the Communications/Social Media committee (led by me).

Membership is currently as follows:

Hypertension News: Lars H. Lindholm, Dylan Burger, Thomas Kahan, Tony Heagerty, Thomas Unger

Communications and Social Media: Dylan Burger, Anastasia Mihailidou, Elena Velkoska, Matias Zanuzzi

In the coming months, we plan to expand our social media reach further and improve communication between ISH committees and its members. We will work closely the May Measurement Month (MMM) team, in particular Lisa Woodward, MMM Communications Manager, as well as the ISH New Investigator and Women in Hypertension Committee.

In particular we will focus on five specific goals:

1. Grow the ISH social media presence and increase readership for Hypertension News

2. Harmonize communication of all ISH news across every distribution platform (Hypertension News, Twitter, Facebook, website, monthly e-bulletin etc.)

3. Assist ISH committees and Regional Advisory Groups (RAGs) in communicating regularly with ISH membership

4. Foster communication with nurses, pharmacists and community health workers who mainly manage hypertension to promote and grow membership of the new ISH Membership category: Health Professional Affiliate (HPA)

5. Ensure that the ISH Communications Committee is serving the needs of membership by monitoring activity and engagement and identifying areas of strength/weakness

In the spirit of improving communication amongst ISH members I intend to compile a list of ISH member Twitter accounts to allow for greater communication. If you are not already doing so, please follow @ISHBP on Twitter and please send a private message via the Twitter page indicating that you are an ISH member.

If you are not yet a Twitter user, I would encourage you to consider joining. Twitter is an excellent resource for researching topics, networking, and increasing the reach of your work. Please click the following link to read a very helpful resource for more information about Twitter in the research environment at: http://www.emeraldgrouppublishing.com/about/pdf/Twitter academics.pdf 